\title{
A comparison of power and flow characteristics between batch and in-line rotor-stator mixers
}

DOI:

10.1016/j.ces.2019.03.015

Document Version

Accepted author manuscript

Link to publication record in Manchester Research Explorer

\section{Citation for published version (APA):}

John, T., Pereira Da Fonte, C., Kowalski, A., \& Rodgers, T. (2019). A comparison of power and flow characteristics between batch and in-line rotor-stator mixers. Chemical Engineering Science.

https://doi.org/10.1016/j.ces.2019.03.015

\section{Published in:}

Chemical Engineering Science

\section{Citing this paper}

Please note that where the full-text provided on Manchester Research Explorer is the Author Accepted Manuscript or Proof version this may differ from the final Published version. If citing, it is advised that you check and use the publisher's definitive version.

\section{General rights}

Copyright and moral rights for the publications made accessible in the Research Explorer are retained by the authors and/or other copyright owners and it is a condition of accessing publications that users recognise and abide by the legal requirements associated with these rights.

\section{Takedown policy}

If you believe that this document breaches copyright please refer to the University of Manchester's Takedown Procedures [http://man.ac.uk/04Y6Bo] or contact uml.scholarlycommunications@manchester.ac.uk providing relevant details, so we can investigate your claim.

\section{OPEN ACCESS}




\title{
A comparison of power and flow characteristics between batch and in-line rotor-stator mixers
}

\author{
T.P. John ${ }^{\mathrm{a}, *}$ C.P. Fonte ${ }^{\mathrm{a}}$, A. Kowalski ${ }^{\mathrm{b}}$, T.L. Rodgers ${ }^{\mathrm{a}}$ \\ ${ }^{a}$ School of Chemical Engineering and Analytical Science, The University of Manchester, \\ Manchester M13 9PL, UK \\ ${ }^{b}$ Unilever R \& D, Port Sunlight Laboratory, Quarry Road East, Bebington, Wirral CH63 \\ उJW, UK
}

\begin{abstract}
Rotor-stator mixers are used in many industries to perform emulsification and de-agglomeration processes. Despite previous research, different modes of operation have not been compared in terms of flow and power characteristics. The aim of this study was to use CFD to investigate power and flow characteristics of a Silverson L5M mixer operating in batch and in-line mode. MRF was used along with the standard $k-\epsilon$ turbulence model for the simulations. Results suggest that batch mixers can be characterised in the same was as in-line mixers, and for a given mixing head design, the characterisation is independent of the mode of operation. A new way of the calculating flow number is proposed, which explains some discrepant results from previous studies. Overall, this work enhances our understanding of rotor-stator mixers and allows for better design choices of mixer.
\end{abstract}

Keywords: Rotor-stator. Mixing. Power number. Flow number. CFD.

\footnotetext{
*Corresponding author

Email address: thomas.john@manchester.ac.uk (T.P. John)
} 


\section{Nomenclature}

\section{Symbols}

$\mathrm{Po}_{1} \quad$ Power number constant

$\mathrm{PO}_{2} \quad$ Power number constant

$\mathrm{POZ}_{\mathrm{Z}} \quad$ Power number constant

U Velocity vector

$\mathrm{ms}^{-1}$

$A_{h} \quad$ Total open area of stator holes

$\mathrm{m}^{2}$

D Rotor diameter

$\mathrm{m}$

$D_{h} \quad$ Stator hole diameter

$\mathrm{mm}$

$k_{1} \quad$ Empirical constant

$k_{2} \quad$ Empirical constant

M Torque

$\mathrm{Nm}$

$N \quad$ Rotor speed

$\mathrm{S}^{-1}$

P Power

W

$p \quad$ Dynamic pressure

$\mathrm{N} \mathrm{m}^{-2}$

$P_{L} \quad$ Power losses

W

$Q \quad$ Volumetric flow rate

$\mathrm{m}^{3} \mathrm{~s}^{-1}$

$R_{b} \quad$ Base hole radius

$\mathrm{m}$

$R_{h} \quad$ Hydraulic radius

$\mathrm{m}$

$S \quad$ Surface area

$\mathrm{m}^{2}$

$S_{i j} \quad$ Strain rate tensor

$\mathrm{m} \mathrm{s}^{-2}$

$T \quad$ Tank diameter

$\mathrm{m}$

V Volume

$\mathrm{m}^{3}$

$v_{n} \quad$ Normal velocity

$\mathrm{m} \mathrm{s}^{-1}$

\section{Greek symbols}


$\mu \quad$ Dynamic viscosity

$\rho \quad$ Density

$\tau \quad$ Stress tensor

\section{Dimensionless numbers}

$\mathrm{Eu} \quad$ Euler number

$\mathrm{N}_{\mathrm{Q}} \quad$ Flow number

$\mathrm{N}_{\mathrm{Q}, \mathrm{i}} \quad$ Imposed flow number

$\mathrm{N}_{\mathrm{Q}, \mathrm{r}} \quad$ Recirculating flow number

$\mathrm{N}_{\mathrm{Q}, \mathrm{t}}$ Total flow number

Po Power number

Abbreviations

CFD Computational Fluid Dynamics

MRF Multiple Reference Frame

PIV Particle Image Velocimetry

$$
\begin{aligned}
& \mathrm{kg} \mathrm{m} \mathrm{m}^{-1} \mathrm{~s}^{-1} \\
& \mathrm{~kg} \mathrm{~m} \mathrm{~m}^{-3} \\
& \mathrm{~N} \mathrm{~m}^{-2}
\end{aligned}
$$

$$
\begin{gathered}
\Delta p / \rho v^{2} \\
Q / N D^{3} \\
Q_{i} / N D^{3} \\
Q_{r} / N D^{3} \\
Q_{t} / N D^{3} \\
P / \rho N^{3} D^{5}
\end{gathered}
$$


1

2

\section{Introduction}

Rotor-stator mixers are mixing devices consisting of one or more high speed rotors, each enclosed within a stationary screen known as a stator. The high speed of the rotors combined with the close proximity of the rotors and the stators allows rotor-stator mixers to generate very high shear rates, hence they are also commonly referred to as high shear mixers. They are highly suitable for processes which require localised intense mixing such as emulsification and de-agglomeration (Atiemo-obeng et al., 2004). Although they have found widespread use in many industries, including chemical, cosmetics, agricultural, food and pharmaceutical, there is still a lack of understanding as to how these mixers truly operate. A particular case of this is in the characterisation and prediction of agitation power. Rotor-stator mixers can operate in either batch or continuous mode. Batch mode is usually preferred for laboratory and pilot scale testing, while continuous mode is usually preferred for large scale processing (Håkansson et al., 2017). Therefore, scale-up of a process involving a rotor-stator mixer typically involves not only a change in size, but also a change in mode of operation. There has been much interest recently in the development and use of a model to predict agitation power in continuous rotor-stator mixers operating in the fully turbulent regime (Kowalski, 2009; Cooke et al., 2011; Hall et al., 2011; Kowalski et al., 2011; Özcan-Taşkin et al., 2011; Jasińska et al., 2015). The model typically used for continuous rotor-stators is given by

$$
P=\mathrm{Po}_{\mathrm{Z}} \rho N^{3} D^{5}+k_{1} \rho Q N^{2} D^{2}+P_{L}
$$

23 which, assuming negligible power losses, can be rearranged to yield 


$$
\mathrm{Po}=\mathrm{PoZ}_{\mathrm{Z}}+k_{1} \mathrm{~N}_{\mathrm{Q}}
$$

where $\mathrm{Po}$ is the dimensionless power number, $\mathrm{Poz}_{\mathrm{Z}}$ can be thought of as the power number with no flow through the mixer, $k_{1}$ is an empirical constant, and $\mathrm{N}_{\mathrm{Q}}$ is the dimensionless flow or pumping number. $\mathrm{N}_{\mathrm{Q}}$ is given by

$$
\mathrm{N}_{\mathrm{Q}}=\frac{Q}{N D^{3}}
$$

The model shown in Equation (1) states that the total power draw of the mixer is the sum of two components, the first being a power required to overcome the drag force as the rotor rotates within the fluid, and the second being the power needed to pump the fluid through the mixing head. The constant $k_{1}$, by which the second component is multiplied, varies between different designs of in-line mixers. The effect of stator or rotor design on the magnitude of this constant has not yet been systematically investigated, although it has already been stated that to do this would be highly advantageous in terms of the mechanical design of these mixers (Håkansson, 2018).

As the flow rate imposed by the external pump approaches zero in inline rotor-stators, there is a deviation of the power number away from the model expressed in Equation (1). The power number can begin to level out or, in certain cases, it can actually increase sharply as the flow number decreases. The power number seems to level off mostly in mixers with a single screen, whereas the increase in power numbers is seen solely in mixers with a double-screen configuration. This has been recorded both using experimental measurements and CFD predictions (Jasińska et al., 2015), and a new model to replace Equation (2) has even been developed in order to account for this 
phenomenon at low flow rates. This model is as follows

$$
\mathrm{Po}=\mathrm{Po}_{\mathrm{Z}}+k_{1} \mathrm{~N}_{\mathrm{Q}}+\frac{\left(\mathrm{Po}_{1}+\mathrm{k}_{2} \mathrm{~N}_{\mathrm{Q}}\right)+\left|\mathrm{Po}_{1}+\mathrm{k}_{2} \mathrm{~N}_{\mathrm{Q}}\right|}{2}
$$

where $\mathrm{Po}_{1}$ and $k_{2}$ are empirical constants which are used to describe the deviation at low flow numbers. There have been multiple suggestions made as to what causes this phenomenon. Recirculation in the holes has been suggested to be one of the causes, but this has not been thoroughly discussed in literature.

Despite the development and use of the model for continuous mixers, there has been relatively little effort to characterise batch rotor-stators in a similar manner. One reason for this is that it is not a simple task to change or measure the flow rate in a batch rotor-stator, as it is in a continuous one. To measure the flow, one must use either complex flow characterisation techniques, such as Particle Image Velocimetry or Laser Doppler Anemometry, or alternatively resort to simulation and use a well validated computationl fluid dynamics (CFD) model. To change $\mathrm{N}_{\mathrm{Q}}$ in a batch rotor-stator with a given screen design, one must change the geometry of the base of the stator, since the rotational speed and diameter of the rotor are both coupled to the flow rate. Previous studies have generally attempted to characterise power and flow in batch rotor-stators based on the geometry of the mixer, since the flow number is not easily known.

Utomo et al. (2009) investigated power draw and flow pattern in a Silverson L4M batch rotor-stator with various stator geometries using CFD. The geometries investigated were the slotted head, the disintegrating head, and the square hole head. For these geometries, the authors suggested that 
the power number scales with the total area of the holes/slots in the stator. James et al. (2017) investigated scale-up of key power parameters for three Silverson batch rotor-stators of varying scale. These were the L5M, the AX3, and the GX10. It was found that the power number is practically constant in the fully turbulent regime. The power number in the fully turbulent regime was also found to be proportional to the total area of the holes/slots in the stator according to the following model:

$$
\mathrm{Po}=1.60\left(\frac{\min \left(R_{h}\right)}{D}\right)^{2}+1.20
$$

where $\min \left(R_{h}\right)$ is the hydraulic radius of either the holes in the screen or the base hole, depending on which is the smallest, and both 1.60 and 1.20 are empirical constants obtained from the experimental data. Note that this model takes the same form as the continuous model, Equation (2), however the flow rate is not required. One drawback of both of these studies is that the geometries investigated differ in many ways. For example, the number, size, and position of the holes/slots change in each geometry. These studies, therefore, do not provide much insight as to which geometrical parameters are actually important for characterising power and flow. It is far more beneficial to investigate stator geometries in which only one geometrical dimension is changing at any one time. Mortensen et al. (2017) conducted a study in this manner, investigating the effect of stator geometry on flow for a batch rotor-stator with a slotted head using PIV. The width of slots was varied in this study, however the number of slots was changed in order to keep the total area constant. The results suggest that the flow number, and hence also power number, actually decreased with increasing slot width, despite a 
constant total area. These results contradict those of Utomo et al. (2009) and James et al. (2017). It is clear from the literature that characterising batch rotor-stators based on mixer geometry is no easy task and that a robust model for predicting agitation power in batch rotor-stators has not yet been found.

Håkansson et al. (2017) simulated an in-line rotor-stator under typical operating conditions for the in-line mixer, ie. lower $\mathrm{N}_{\mathrm{Q}}$, and also conditions relating to the typical operation of a batch rotor-stator, ie. higher $\mathrm{N}_{\mathrm{Q}}$. Differences in rotor-stator hydrodynamics and the implications with regards to emulsification are explained using a number known as the fill ratio, which is essentially the ratio of the average fluid velocity through the holes in the screen and the rotor tip speed, or the fraction of the holes actually occupied by the high velocity jets leaving the stator. This study concluded that at high values of $\mathrm{N}_{\mathrm{Q}}$ the CFD results were very similar to PIV results for a batch rotor-stator, indicating that for a given rotor and stator design, there is in fact a hydrodynamic similarity between the two modes of operation. This, however, has not yet been investigated further. Something similar was suggested from results obtained by Carrillo De Hert and Rodgers (2017); that droplet break-up in the different modes of operation could be linked using a mass balance and accounting for the residence time of the droplets actually in the mixing head.

The aims of this study were to investigate characteristics of power and flow in batch rotor-stator mixers using CFD with experimental validation, and to compare the characterisation with previously developed models for in-line mixers. This study will make use of systematic geometry changes 
in order to obtain the most beneficial results and conclusions. In doing so, our understanding of flow dynamics in rotor-stator mixers will be enhanced, benefiting both researchers in this field and also industries using these mixers to carry out their processes.

\section{Materials and Methods}

\subsection{CFD model}

The rotor-stator mixer investigated in this study is the Silverson L5M batch, laboratory scale mixer. In its standard configuration it is a batch mixer, however, an in-line mixing assembly can be fitted over the mixing head to switch the mode of operation. The two configurations of the mixer can be seen in Figure 1. The standard emulsor screen was chosen as the stator design in all cases, which consists of 6 staggered rows of 39 holes (Figure 2). For the batch configuration, the mixing head was positioned in the center, both vertically and horizontally, of a tank of diameter $137 \mathrm{~mm}$. The height of the fluid was equal to the diameter of the tank and the tank contained 4 baffles of length $T / 10$, where $T$ is the tank diameter. The fluid used in all cases was water. For the batch mixer, the base of the stator was constricted in several increments in order to change the flow rate of fluid through the mixing head independently of the rotor speed, hence varying $\mathrm{N}_{\mathrm{Q}}$. 


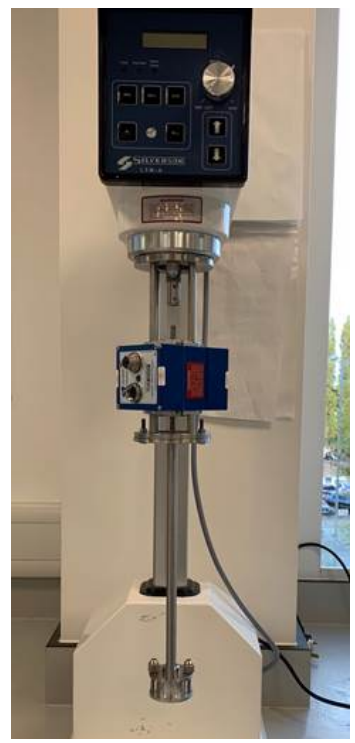

(a)

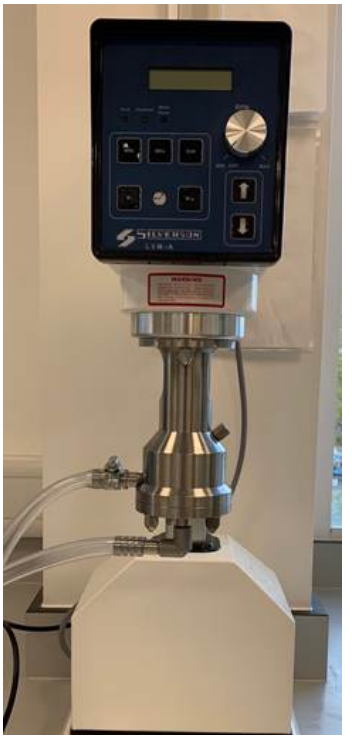

(b)

Figure 1: Silverson L5M configured in (a) batch mode with the TorqueSense torque meter, and (b) continuous or in-line mode using the in-line mixing assembly.

A hybrid mesh containing 14 million elements was used for the batch simulations. Preliminary mesh independent tests have shown independence of the results with meshes of this level of refinement. The mesh was refined in the proximity of the mixing head so that at least 10 elements were present between the rotor and the stator. Proximity and curvature functions were used to refine the mesh around the shaft. 


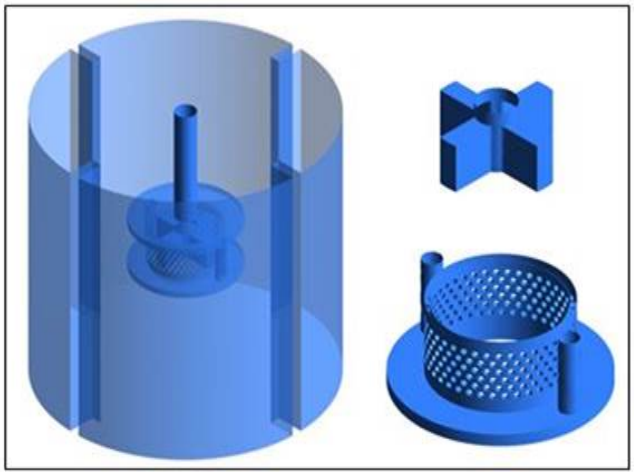

(a)

\subsection{Simulations}

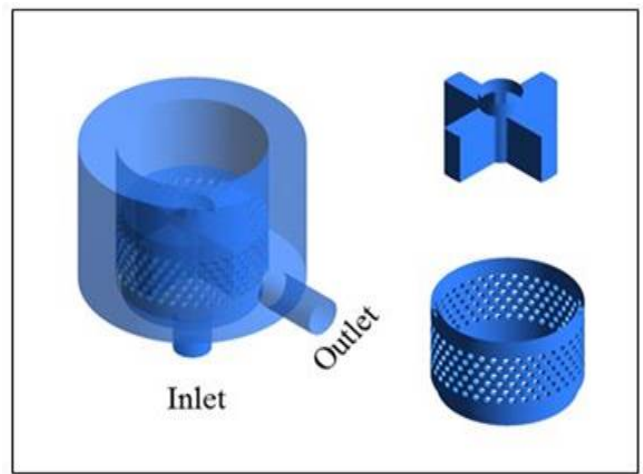

(b)

Figure 2: CFD geometry for Silverson L5M configured in (a) batch mode and (b) continuous or in-line mode.

ANSYS Fluent version 18.1 was used to run each simulation. Simulations were run on 12 cores. All simulations were steady-state, with the MRF technique employed to model rotor rotation. The cylindrical MRF interface was positioned exactly in the middle of the rotor-stator gap. A previous study suggested that CFD simulation of rotor-stators should only be carried out using the transient Sliding Mesh technique due to the periodicity of the power and the flow as the rotor moves past the holes/slots (Mortensen et al., 2018). However, the holes of the standard emulsor screen are small, closely spaced, and staggered in between rows. This means that the periodicity of power and flow will be much smaller than in other stators, and therefore the MRF technique is adequate. As is good practice in any CFD investigation using MRF, multiple rotor positions were tested in order to validate this. The standard $k-\epsilon$ turbulence model was used along with the standard wall function to model the near-wall, viscosity affected region. This model is 
well-known to under predict turbulent dissipation, however in this particular study, turbulent dissipation is of relevantly little concern due to the fact that turbulent transport of species or other phenomena such as droplet break-up is not being modelled. The $k-\epsilon$ turbulence models have been widely used with success to predict mean flow properties in both batch and in-line rotor-stator mixers (Håkansson et al., 2017; Jasińska et al., 2015; Minnick et al., 2018; Mortensen et al., 2018; Özcan-Taşkin et al., 2011; Utomo et al., 2008, 2009). Spatial discretisation of momentum and turbulence was achieved using the third order MUSCL scheme, the gradient using least squares cell based, and the pressure using PRESTO!. Under-relaxation factors were kept as their default values. The no-slip condition was specified at all solid walls, ie. tank walls, shaft, rotor and stator, so that $\mathbf{U}=\mathbf{0}$ at the wall. The water-air interface at the top of the tank was modelled by specifying a shear of zero at the interface, so that $\boldsymbol{\tau}=\mathbf{0}$ at the wall. For in-line simulations, the inlet was specified as a velocity inlet and the outlet was specified as a pressure outlet. 


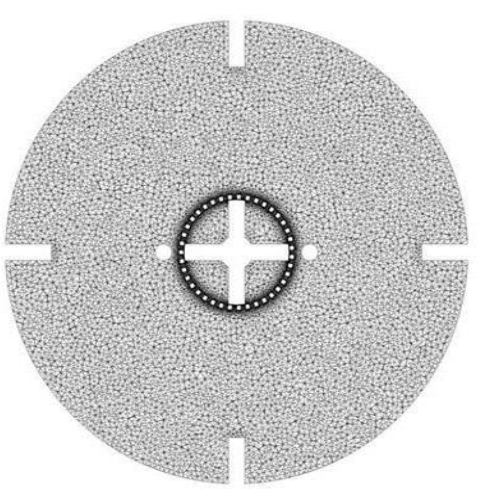

(a)

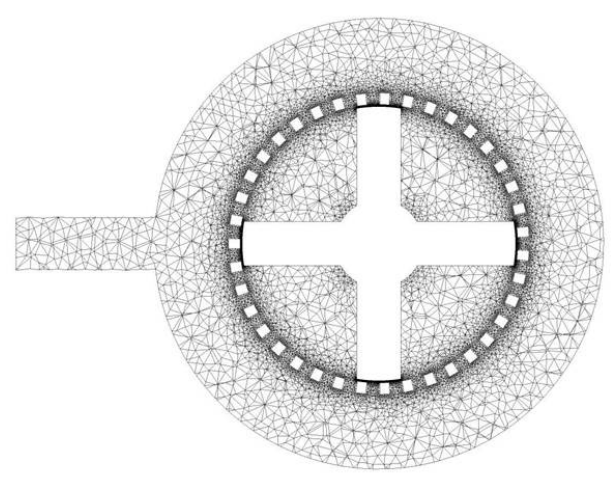

(c)

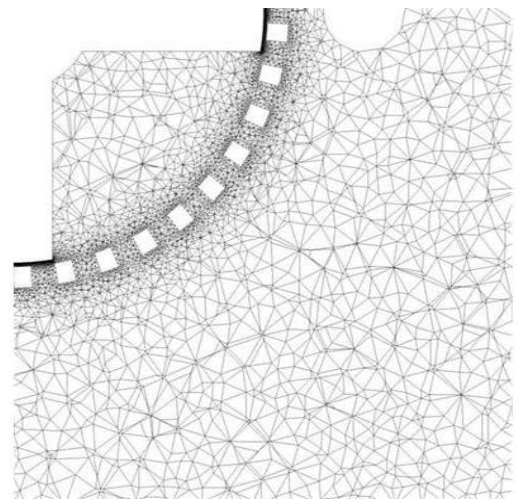

(b)

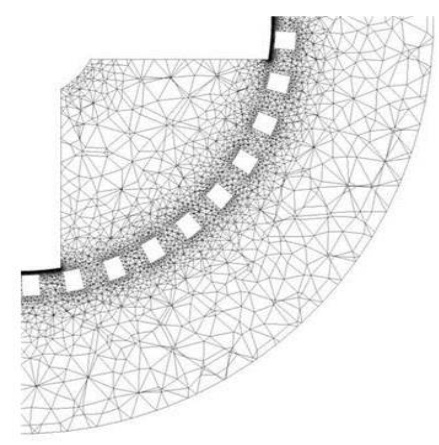

(d)

Figure 3: CFD mesh for (a) and (b) batch rotor-stator, and (c) and (d) in-line rotor-stator.

171 The criteria for solution convergence were that the residuals for all solved flow 172 and turbulence equations were stabilised and the total bending moments on 173 the rotor were constant with respect to the iteration number. 


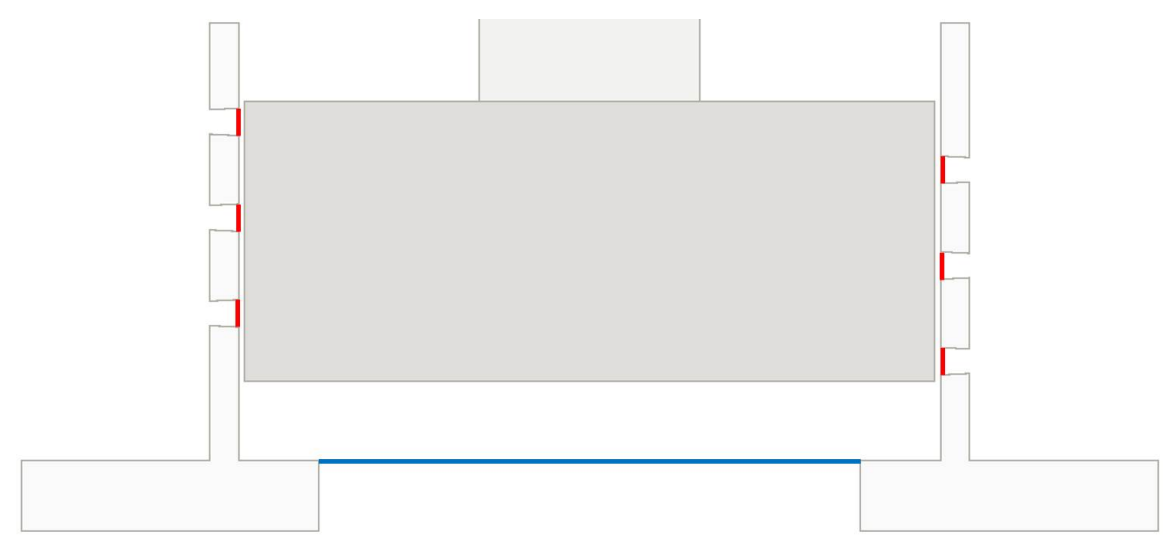

Figure 4: Cross section of Silverson L5M mixing head. Red lines show surface used to calculate radial flow through the holes of the stator. Blue line shows surface used to calculate axial flow through the base of the stator.

For the batch rotor-stator, the flow rate was calculated across two surfaces. The first was at the inside entrance to the holes of the stator, ie. the inner radius of the stator screen. The second position is at the top of the base of the stator. These surfaces are shown in Figure 4. Since there is flow in both directions on both of the surfaces, the positive and negative flows, for both the radial flow through the holes and the axial flow through the base, were calculated respectively as follows

$$
\begin{aligned}
Q_{+v e} & =\frac{\iint_{S}\left|v_{n}\right| \mathrm{d} S+\iint_{S} v_{n} \mathrm{~d} S}{2} \\
Q_{-v e} & =\frac{\iint_{S}\left|v_{n}\right| \mathrm{d} S-\iint_{S} v_{n} \mathrm{~d} S}{2}
\end{aligned}
$$

where $Q_{+v e}$ and $Q_{-v e}$ are the positive and negative volumetric flow rates respectively in $\mathrm{m}^{3} \mathrm{~s}^{-1}$ with respect to the direction of the cylindrical axis, and $v_{n}$ is the velocity component normal to the surface, $S$, across which the 
flow is calculated, ie. radial velocity for flow through the holes and axial velocity for flow through the base. The flow for the in-line rotor-stator was calculated in exactly the same manner, except axial flow was measured across the inlet boundary instead of the base of the stator.

The power draw from the rotor can be calculated using several methods. One commonly used method is to calculate the power using the total energy dissipation:

$$
P=\rho \iiint_{V} \epsilon \mathrm{d} V+2 \mu \iiint_{V} \bar{S}_{i j} \bar{S}_{j i} \mathrm{~d} V
$$

where $V$ is the total volume of fluid, $\epsilon$ is the turbulent dissipation rate, $\mu$ is the dynamic viscosity, and $S_{i j}$ is the strain rate tensor. The first term on the right hand side of the equation represents the energy dissipated due to turbulent fluctuations whilst the second term represents the energy dissipated due to the mean flow.

The second method is to evaluate the bending moments on the rotor by integrating the pressure across all of the solid surfaces of the rotor. It is generally accepted that the latter method is more accurate when a RANS turbulence model is used, since all RANS turbulence models under-predict turbulent dissipation (Rielly and Gimbun, 2009). It is for this reason that the power in this study is solely calculated using the bending moment on the rotor:

$$
P=2 \pi N M
$$

203 where $M$ is torque or bending moment. 


\subsection{Experimental validation}

Experimental validation of the CFD power predictions was carried out using a Silverson L5M custom fitted with a $1 \mathrm{Nm}$ TorqueSense torque meter. The torque was measured at rotor speeds between $2000 \mathrm{~min}^{-1}$ and $7500 \mathrm{~min}^{-1}$ in $500 \mathrm{~min}^{-1}$ increments. To reduce error, the torque losses due to the bearings were measured before and after each run by measuring the torque of the mixer in air as opposed to water at the same speeds as the actual experimental runs. These values were then subtracted from the values obtained in the experimental runs in water.

\section{Results and discussion}

In the following section, the results from this study will be presented and discussed. Results regarding the validation of the CFD model can be found in the supporting information for this paper.

\subsection{Varying base diameter in batch mode of operation}

Figure 5 shows the effect of varying the base diameter of the stator with various screen hole sizes on the power number of the mixer. Note that when $R_{b}=0$, the base is fully closed so there is no flow through the base. For each screen hole size, the power number generally follows the same trend as the base diameter is varied. At low base diameters, the power number increases exponentially with the base diameter. This can be expected due to the fact that the hydraulic radius of the base hole is much smaller than the hydraulic radius of the holes in the screen, so the power is controlled by the flow into the base. Therefore, the power is expected to be proportional to the area of the base hole, $\mathrm{Po} \propto R_{b}{ }^{2}$. As the base hole is opened, the 
flow becomes restricted by the holes in the screen and so the power number reaches a plateau, whose magnitude depends on the size or area of the holes. Once the base is opened even further, flow begins to exit through the base of the stator as well as through the holes. The point at which this base flow begins is dependent on the size or area of the holes in the screen.

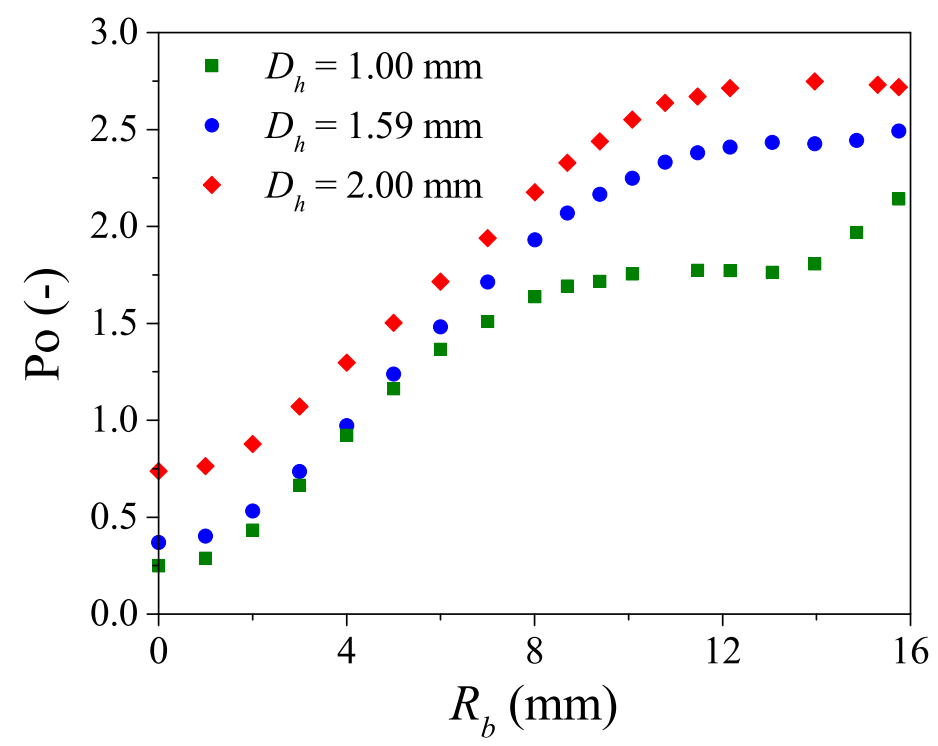

Figure 5: Power number as a function of base hole radius for various screen hole sizes. 


\subsection{Effect of varying flow number on power number in batch rotor-stators}

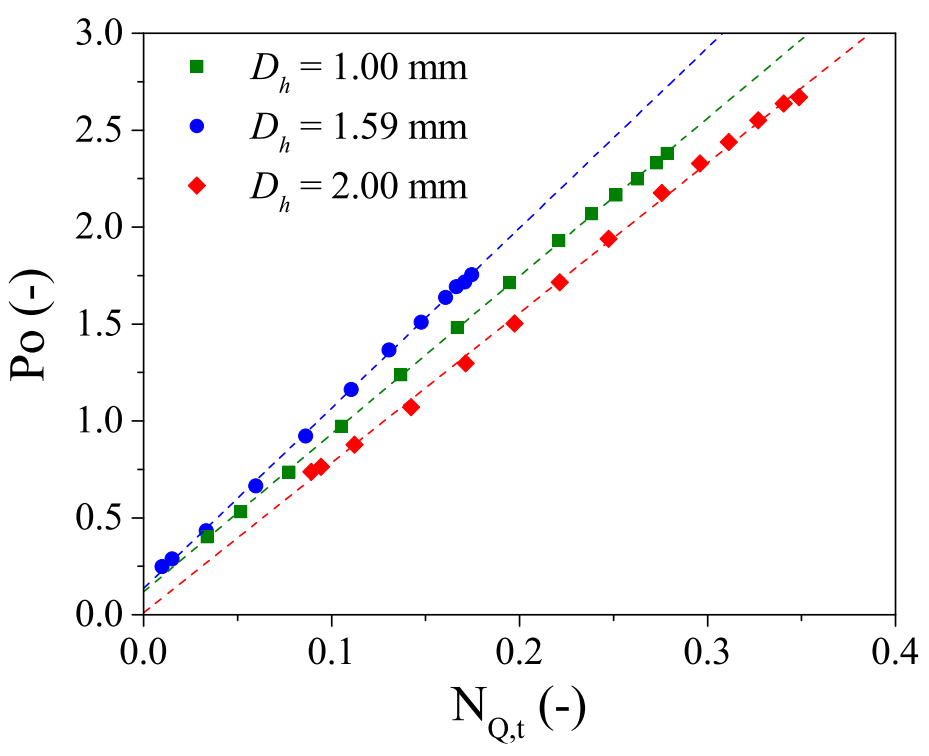

Figure 6: Power number as a function of flow number in batch mode for various screen hole sizes.

As discussed in Section 1, the effect of varying flow number on power number for a given stator design or geometry has not been previously studied for batch rotor-stators. Figure 6 shows the power number as a function of the flow number for the batch simulations. In this case, the flow rate used in the calculation for $\mathrm{N}_{\mathrm{Q}}$ was the total flow rate exiting the mixing head. For this part of the study, the only data considered is that in which there is no negative axial flow through the base of the stator, therefore the total flow out of the stator is equal to the positive radial flow through the inside surface of the holes. The effect of $\mathrm{N}_{\mathrm{Q}}$ on Po is shown for three different hole sizes in the screen. For each hole size, the results suggest there is a strong linear relationship between the two variables, and that ultimately, batch rotorstators with no flow exiting the base of the stator can be characterised in a 
Table 1: Values of $k_{1}$ and $\mathrm{Poz}_{\mathrm{Z}}$ for Silverson L5M standard emulsor head with various hole sizes.

\begin{tabular}{ccccc}
\hline$D_{h}(\mathrm{~mm})$ & $k_{1}$ & $\mathrm{SE}_{1}$ & $\mathrm{PO}_{\mathrm{Z}}$ & $\mathrm{SE}_{2}$ \\
\hline 1.00 & 9.30 & 0.070 & 0.14 & 0.0084 \\
1.59 & 8.14 & 0.031 & 0.12 & 0.0060 \\
2.00 & 7.74 & 0.088 & 0.010 & 0.021 \\
\hline${ }^{*} S E_{1}$ and $S E_{2}$ are the standard errors for $k_{1}$ & and $\mathrm{PoZ}_{\mathrm{Z}}$ respectively. \\
\hline
\end{tabular}

similar fashion to in-line-rotor stators. The lowest flow number for each hole size in Figure 6 was obtained by completely closing the base of the stator, so in this particular case there is no axial flow, either positive or negative, through the base of the stator. It is therefore interesting to note here that this strong linear relationship still exists for these geometries, since all of the flow into and out of the stator is occurring through the holes in the screen and not through the base of the stator.

The values of the empirical constants $k_{1}$ and $\mathrm{Po}_{\mathrm{Z}}$ obtained for the batch simulations are shown in Table 1. Comparing these values to values recorded in literature for in-line rotor stators (Håkansson, 2018), it can be seen that there is much similarity. This adds further validation to both the accuracy of our CFD model and also the conclusion that batch and in-line rotorstators can be characterised in the same manner. These results also suggest that $k_{1}$ is dependent partly on the size of the holes in the screen. This can potentially be explained by comparing the flow through the rotor-stator with that through a perforated plate in a pipe. The Euler, Eu, number can be thought of as the ratio of the pressure forces to the inertial forces. It is of particular interest in fluid flows where pressure drop is important, such as the flow through the screen of a rotor-stator mixer. Here, we define that 
Euler number as

$$
\mathrm{Eu}=\frac{\Delta p}{\rho N^{2} D^{2}}
$$

where $\Delta p$ is the pressure drop. Therefore

$$
P=\mathrm{Po}_{\mathrm{Z}} \rho N^{3} D^{5}+\Delta p Q=\mathrm{Po}_{\mathrm{Z}} \rho N^{3} D^{5}+\operatorname{Eu} \rho N^{2} D^{2} Q
$$

which can be rearranged to give

$$
\mathrm{Po}=\mathrm{Poz}_{\mathrm{Z}}+\mathrm{EuN}_{\mathrm{Q}}
$$

Equation (12) shows that the second term in the full power number equation, Equation (1), can be obtained by either considering the acceleration of fluid due to the rotor, or by the pressure drop created by the rotor and the stator screen, It is therefore evident that $k_{1}$ is related to the Euler number, and since the Euler number varies with the design of the holes in a perforated plate in a pipe (Malavasi et al., 2012), $k_{1}$ will likely vary with the design of the stator. The recirculating flow entering the holes from the bulk region will most likely give rise to some differences between $k_{1}$ and the standard definition of the Euler number, but this consideration provides us with a better understanding behind the physical meaning of $k_{1}$ and why it depends on the geometry and design of the mixing head. The effects of geometry changes on $k_{1}$ will not be discussed further here.

\subsection{Comparison between in-line and batch rotor-stators}

Equation (2) was developed solely for in-line rotor-stators due to the fact that the flow number can easily be changed and calculated for a given stator 
design using simply the flow rate in the piping. After considering the way in which the flow rate was calculated for batch rotor-stators in this study, it becomes apparent that comparing the flow in the two modes of operation will give rise to some complications. By using the flow in the pipe to calculate $\mathrm{N}_{\mathrm{Q}}$ in in-line mode, the radial flow rate into the holes is not accounted for, and so the flow rate used does not necessarily equal the total flow rate through the actual screen of the mixing head. Without the use of any data, this fact can already be used to potentially explain the phenomenon that often occurs in in-line rotor-stators at very low flow numbers. At flow numbers approaching zero in in-line mode, the true flow number can not reach zero, since there is still flow entering and exiting through the holes or slots in the screen. This has already been shown in batch mode in Figure 6, and suggests that the phenomenon observed at low flow rates in in-line rotor stators is simply a result of the usage of only a part of the true flow rate in the calculation for $\mathrm{N}_{\mathrm{Q}}$. This is consistent with what was suggested in the study conducted by Jasińska et al. (2015), however this new information suggests that the flow number used in that study, and in the majority of the studies conducted previously in this field, has not been calculated correctly. 


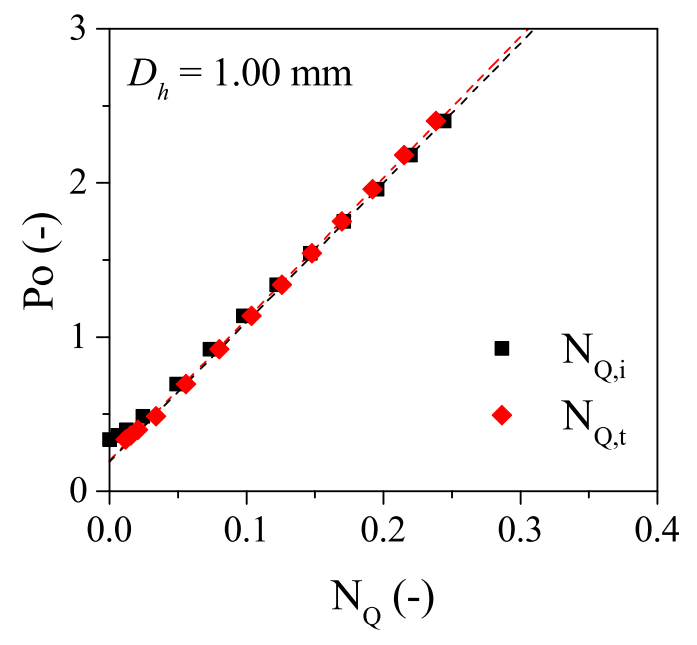

(a)

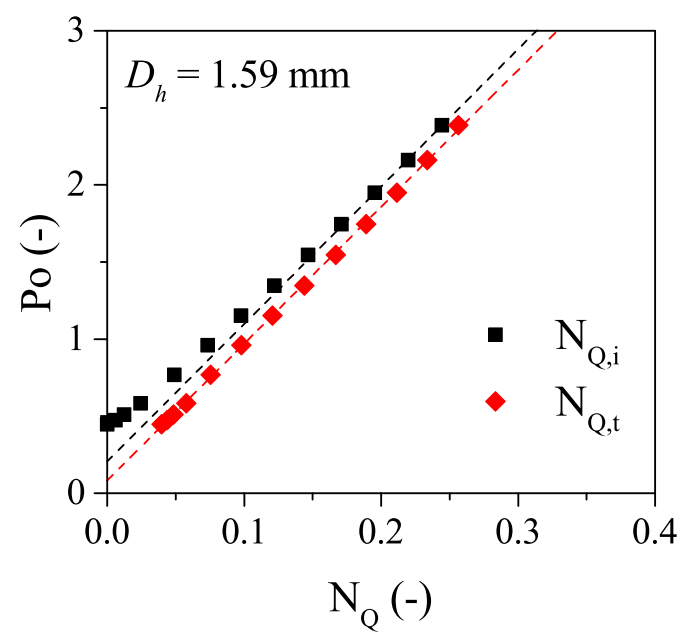

(b)

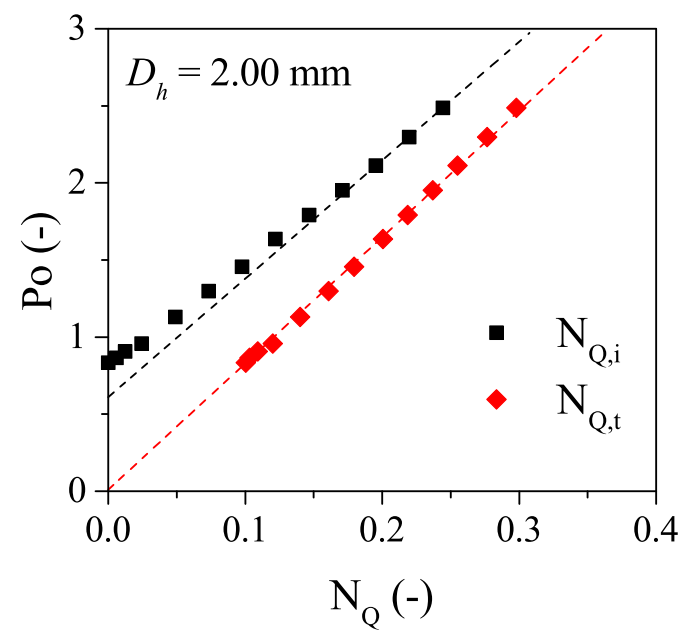

(c)

Figure 7: CFD prediction of power number as a function of flow number for in-line Silverson L5M with screen hole sizes of (a) $1.00 \mathrm{~mm}$, (b) $1.59 \mathrm{~mm}$, (c) $2.00 \mathrm{~mm}$. Black dashed line - Linear fit of high values of $\mathrm{N}_{\mathrm{Q}, \mathrm{i}}$, Red dashed line - Linear fit of $\mathrm{N}_{\mathrm{Q}, \mathrm{t}}$.

Figure 7 displays the power number as a function of the flow number for 
lated in two different ways in order to investigate the effect of recirculation as mentioned previously. The total flow number, $\mathrm{N}_{\mathrm{Q}, \mathrm{t}}$, was calculated using the total positive radial flow across the inside surface of the holes in the screen, ie. the same analysis as batch mode. In-line mixers should exhibit no negative flow through the base, since the base is usually a narrow inlet. The total flow through the stator is therefore the positive radial flow in the holes of the screen. The imposed flow number, $\mathrm{N}_{\mathrm{Q}, \mathrm{i}}$, was calculated using the imposed flow rate at the velocity inlet. This is the way in which the flow number would be calculated experimentally in in-line mixers, using a flow meter positioned in the inlet or outlet pipeline. At high flow numbers when using the imposed flow number, the power number is proportional to the flow number as expected. At low flow numbers, the power number starts to rise above the linear fit. This is very likely the phenomenon which has previously been discussed.

When using the total flow number, the correlation for each hole size shifts in a positive direction with regards to the flow number. This is due to the fact that the flow into the holes of the screen is now being taken into account. It can be also be seen that when using the total flow number, the linear correlation extends down all the way to the lowest data point, at which there is no imposed flow rate. This strongly suggests that the increase in power number at low flow rates is caused by the incorrect estimation of the flow number when using the imposed flow rate in the pipe. This seems logically sound, since there can never truly be zero flow through the stator whilst the rotor is rotating at high speeds. The rise in power number at low flow rates is not as extreme in these results as in results previously obtained (Jasińska 
et al., 2015), however this is likely due to the fact that the in-line mixer used in this study is a single rotor-single stator configuration, whereas previous results were obtained using double rotor-double stator configurations.

Figure 8 shows the power number as a function of the total flow number for the batch and in-line Silverson L5M, as predicted by the CFD simulations. It can clearly be observed that both batch and in-line mixers share the same correlation, and that the the way in which rotor-stator mixers are characterised is not dependent on the mode of operation, but on the design of the rotor and the screen. Although this conclusion has been implicitly suggested previously (Håkansson et al., 2017), no study as of yet has shown explicit evidence of this behavouir of rotor-stator mixers. These results might suggest the same conclusion as that from the study of Carrillo De Hert and Rodgers (2017); that the droplet size distribution of an emulsion produced in a batch rotor-stator can be matched with that produced in an in-line rotor stator by using a mass balance and accounting for the residence time of the droplets actually in the mixing head. The results shown in Figure 8 suggest that for the same flow number, the amount of energy is transferred into the fluid, and hence the amount of energy available for droplet break-up, is practically the same for both modes of operation. 


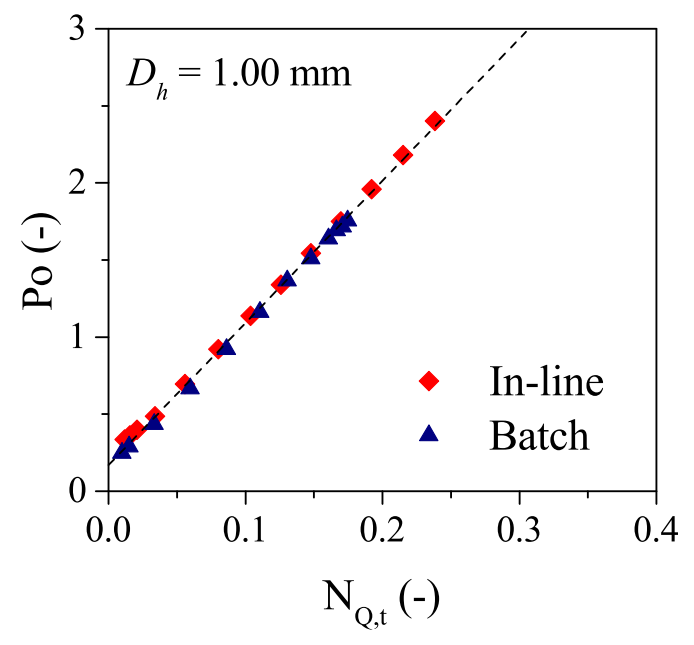

(a)

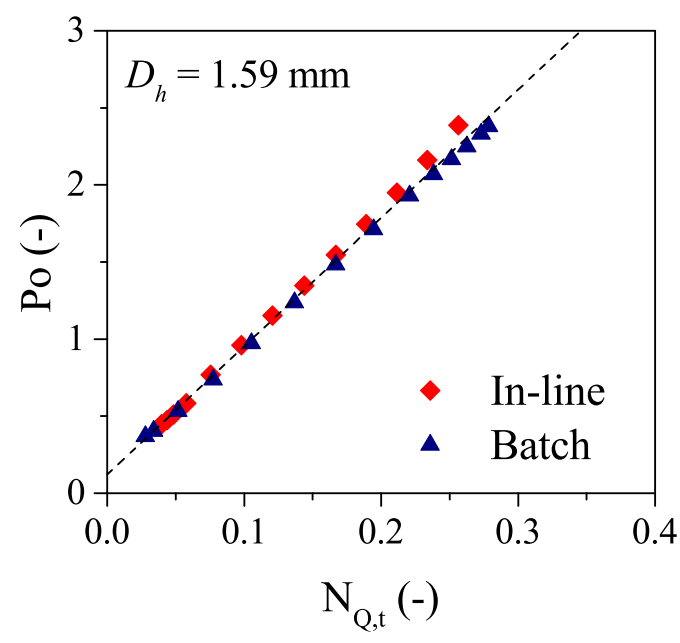

(b)

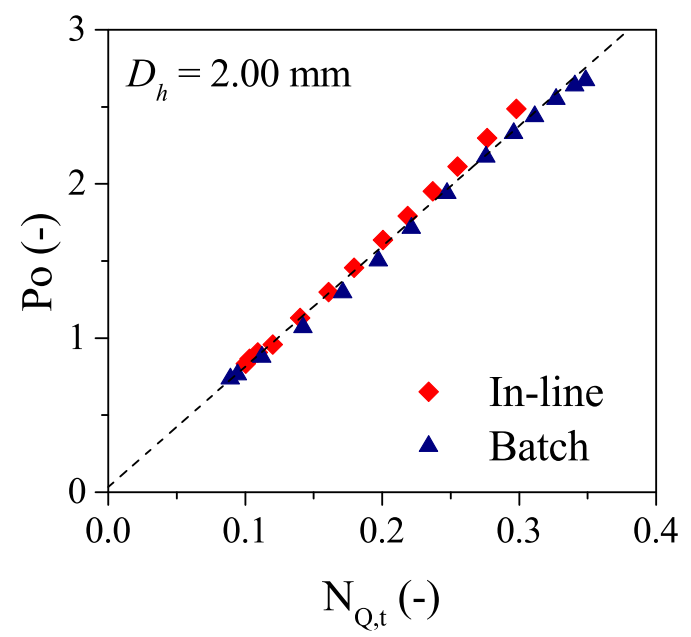

(c)

Figure 8: CFD prediction of power number as a function of total flow number for Silverson L5M mixer operating in batch and in-line mode with screen hole sizes of (a) $1.00 \mathrm{~mm}$, (b) $1.59 \mathrm{~mm}$, (c) $2.00 \mathrm{~mm}$. Black dashed line - Linear fit of concatenated data.

\subsection{Imposed flow rate versus total flow rate in in-line mode of operation}

It is clear from the results discussed in the previous sections that in order to properly characterise power in in-line rotor-stators, one must take into 
account the recirculating flow into the holes of the screen when calculating the flow number of the mixer. In this study we have achieved this using CFD, however optical flow characterisation methods such as PIV could also be used to achieve this. These methods are usually less attractive since they require expensive equipment and collecting data may take too long for it to be a feasible option in industry. It is therefore desirable to develop a model in order to predict the total flow rate from known imposed flow rate and the geometry of the rotor and the stator.

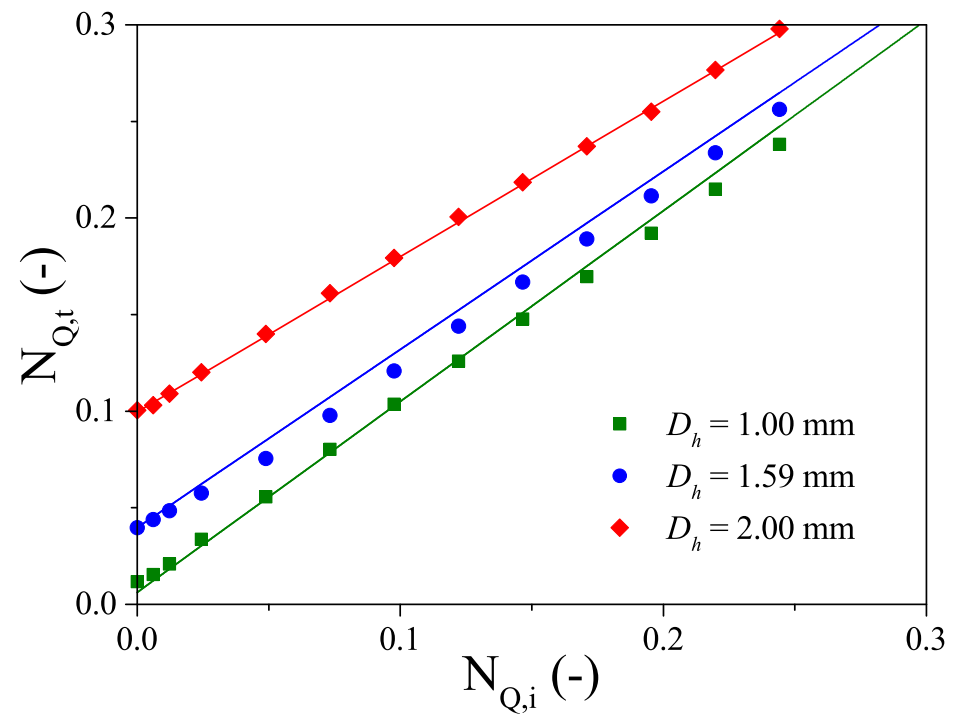

Figure 9: Total flow number as a function of imposed flow number in Silverson L5M with in-line mixing assembly and various screen hole sizes as predicted by CFD. Solid lines show $\mathrm{N}_{\mathrm{Q}, \mathrm{t}}$ predicted by the correlation developed in this study, Equation (13).

Figure 9 shows the total flow rate as a function of the imposed flow rate for various hole sizes in the screen. The results suggest that for each hole size there is a strong linear relationship between the imposed and total flow numbers, however the intercept and the slope vary with hole size or total hole 
area of the screen. The intercept is related to the amount of fluid flowing through the mixer when the inlet and outlet valves are shut, or the amount of fluid flowing into and back out of the holes. This, of course, increases with total area of the holes. It would also make sense physically that this flow scales with the square of the total area of the holes, since flow rate in tubular flows is proportional to $R^{4}$, where $R$ is the radius of the tube or pipe. In this case the tubes are the holes in the screen. The slope of the relationships in Figure 9 describes the relative amount of flow which is entering through the holes in the screen. The slope in Figure 9 was found to inversely proportional to the square of the area of the holes with a $y$ intercept equal to unity. The magnitude of the intercept equalling unity can be expected because theoretically if there were no holes, the total flow would equal the imposed flow. At extremely large areas, it is likely that this relationship will not be linear, but will approach an asymptote near zero, since a negative slope in Figure 9 would seem illogical. Since typical stators would never have such large ratios between the hole area and rotor diameter, it is sufficient to assume a linear relationship with the square of the holes area. This model will also only work for stators with a single screen, since these mixers don't usually exhibit the sharp increase of power number with decreasing flow number at low flow numbers. This trend is observed solely in mixers with a double-screen configuration (Jasińska et al., 2015), in which the flow is much more complex to model in this manner. It is likely that the area is not the only screen geometry variable to use in this correlation, since Mortensen et al. (2017) showed that for the same area, the flow and power numbers can change. The hydraulic radius of the holes in the screen might 
be a good variable to include as this takes into account the effect described in the study just mentioned. This, however, will not be considered in this study.

The following model can therefore be used to predict the total and correct flow number in an in-line rotor-stator

$$
\mathrm{N}_{\mathrm{Q}, \mathrm{t}}=\mathrm{N}_{\mathrm{Q}, \mathrm{i}}+0.33\left(\frac{A_{h}}{D^{2}}\right)^{2}\left[0.51-\mathrm{N}_{\mathrm{Q}, \mathrm{i}}\right]
$$

This model essentially states that the true flow through the mixing head, $\mathrm{N}_{\mathrm{Q}, \mathrm{t}}$, is equal to the imposed flow, $\mathrm{N}_{\mathrm{Q}, \mathrm{i}}$, plus the flow moving back into the rotor swept region through the holes, $\mathrm{N}_{\mathrm{Q}, \mathrm{r}}$, which is a function of the geometry of the rotor and the stator and also the imposed flow number. It should be noted that there are some exceptional cases in which this model cannot possibly be used. For example, when the rotor speed approaches zero, both the imposed and total flow numbers approach infinity. However, when the rotor speed is zero, a flow number in this sense would be of little use anyway. The accuracy of this model is shown in Figure 9 by the solid lines, and also in the parity plot displayed in Figure 10.This correlation is also extremely beneficial in that it provides an easy method for determining the amount of recirculating flow, since the power and imposed flow rates are both easily known to us for in-line mixers. It would therefore also be useful to study how the relative amount of recirculating flow affects the droplet size of an emulsified product, since this correlation could be used to tune the quality of the product based on the mixing head geometry. 


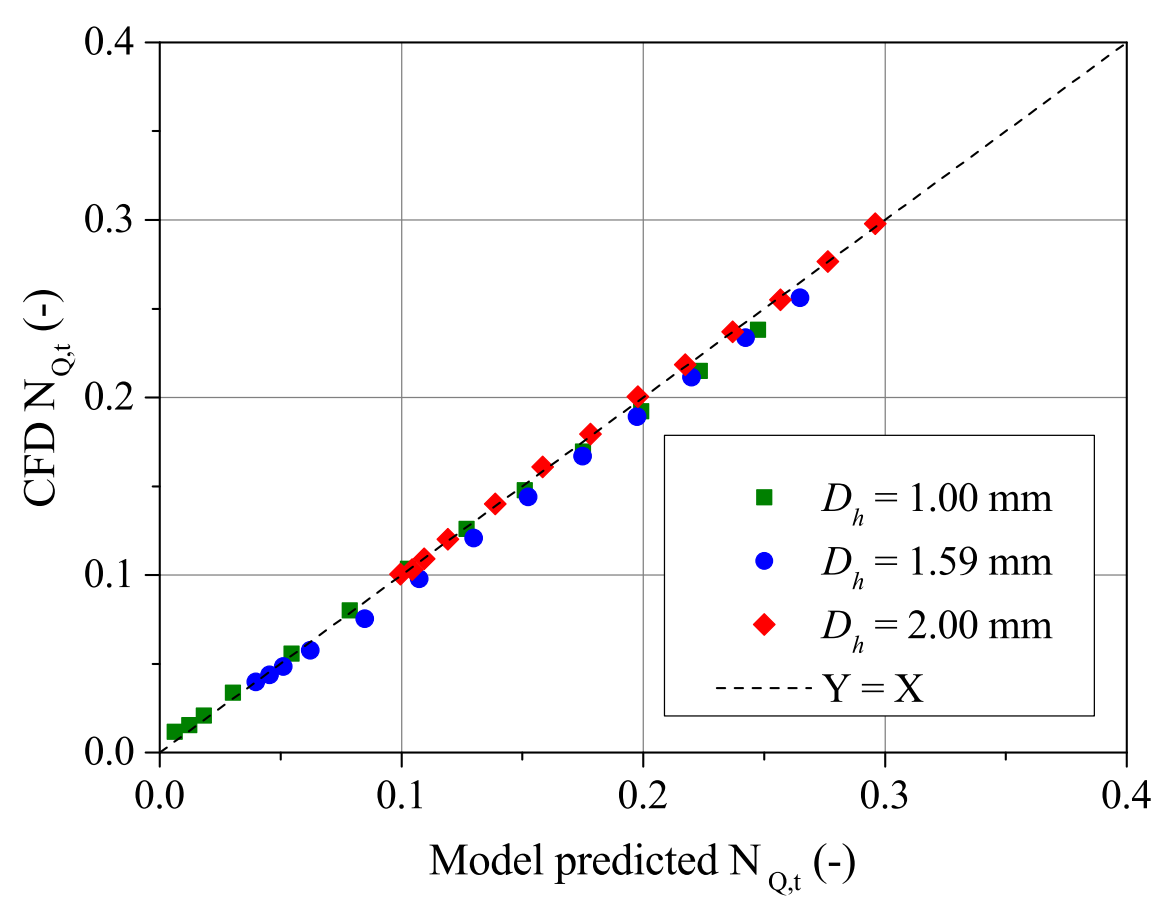

Figure 10: Parity plot for model used to predict total flow number shown in Equation (13).

\section{Conclusions}

In this study, CFD has been used to investigate and compare the power and flow characteristics in a Silverson L5M rotor-stator mixer operating in batch and in-line mode. CFD results were validated with experimental torque measurements. Flow number in the batch mode of operation was varied by constricting the base of the stator. It was found that batch rotor-stator mixers can be characterised using the well developed model which is already in use for in-line mixers, provided that the base is small enough that no flow is allowed to exit through it. For a given design of rotor and stator, the characterisation model is practically the same regardless of whether the mixer is in the batch or the in-line configuration. When the mixer is operating 
in in-line mode, one must take into account not just the imposed flow in the pipeline, but also the recirculating flow entering the holes of the stator. At low imposed flow rates, previous investigations showed a deviation away from the standard model; an increase in power number with decreasing flow number. It can be concluded from this study that this deviation is due to the flow entering the holes at low imposed flow rates. This study also proposes a model which can be used to predict the correct flow number, flow in the pipe plus flow into the holes, based on known operating parameters, namely the geometry of the rotor and stator and also the imposed flow in the pipeline. This correlation can also be used to predict the amount of recirculating flow since the power and imposed flow numbers are easy to measure for in-line mixers. Potentially the correlation could be used to help tune the quality of emulsified products. Overall, this study provides useful insight into the fundamental workings of rotor-stator mixers and will hopefully enable more justified design choices to be made by anyone using a rotor-stator mixer. This study also highlights areas in which further research would be highly beneficial, such as studying the effect of geometry changes on the constant $k_{1}$.

\section{Acknowledgements}

The authors would like to express their gratitude to the EPSRC industrial case awards and Unilever for funding the first authors $\mathrm{PhD}$ studies and EPSRC project The Centre in Advanced Fluid Engineering for Digital Manufacturing (EP/R00482X/1) for funding the other authors. The authors would also like to thank the workshop staff of The University of Manchesters 
School of Chemical Engineering and Analytical Science for their help with the modifications and maintenance of the equipment.

\section{References}

Atiemo-obeng, V.A., Calabrese, R.V., Kresta, S.M., 2004. Rotor Stator Mixing Devices. Handbook of Industrial MIxing- Science and Practice , 479-505.

Carrillo De Hert, S., Rodgers, T.L., 2017. Continuous, recycle and batch emulsification kinetics using a high-shear mixer. Chemical Engineering Science 167, 265-277. URL: http://dx.doi.org/10.1016/j.ces.2017.04.020, doi:10.1016/j.ces.2017.04.020.

Cooke, M., Rodgers, T.L., Kowalski, A.J., 2011. Power consumption characteristics of an in-line silverson high shear mixer. AIChE Journal 58, 1683-1692. URL: http://doi.wiley.com/10.1002/aic.12703, doi:10.1002/aic.12703.

Håkansson, A., 2018. Rotor-Stator Mixers: From Batch to Continuous Mode of OperationA Review. Processes 6, 32. URL: http://www.mdpi.com/2227-9717/6/4/32, doi:10.3390/pr6040032.

Håkansson, A., Arlov, D., Carlsson, F., Innings, F., 2017. Hydrodynamic difference between inline and batch operation of a rotor-stator mixer head - A CFD approach. The Canadian Journal of Chemical Engineering 95, 806-816. URL: http://doi.wiley.com/10.1002/cjce.22718, doi:10.1002/cjce.22718.

Hall, S., Cooke, M., Pacek, A.W., Kowalski, A.J., Rothman, D., 2011. Scaling up of silverson rotor-stator mixers. The Canadian Journal of Chemical Engineering 89, 10401050. URL: http://doi.wiley.com/10.1002/cjce.20556, doi:10.1002/cjce.20556.

James, J., Cooke, M., Trinh, L., Hou, R., Martin, P., Kowalski, A., Rodgers, T.L., 2017. Scale-up of batch rotorstator mixers. Part 1power constants. Chemical Engineering Research and Design 124, 313-320. URL: http://www.sciencedirect.com/science/article/pii/S0263876217303490, doi:https://doi.org/10.1016/j.cherd.2017.06.020.

Jasińska, M., Bałdyga, J., Cooke, M., Kowalski, A.J., 2015. Specific features of power characteristics of in-line rotorstator mixers. Chemical Engineering and Processing: Process Intensification 91, 43-56. URL: http://linkinghub.elsevier.com/retrieve/pii/S0255270115000720, doi:10.1016/j.cep.2015.03.015.

Kowalski, A.J., 2009. An expression for the power consumption of in-line rotor-stator devices. Chemical Engineering and Processing: Process Intensification 48, 581585. URL: http://linkinghub.elsevier.com/retrieve/pii/S0255270108000998, doi:10.1016/j.cep.2008.04.002. 
Kowalski, A.J., Cooke, M., Hall, S., 2011. Expression for turbulent power draw of an in-line Silverson high shear mixer. Chemical Engineering Science 66, 241-249. URL: http://dx.doi.org/10.1016/j.ces.2010.10.010, doi:10.1016/j.ces.2010.10.010.

Malavasi, S., Messa, G., Fratino, U., Pagano, A., 2012. On the pressure losses through perforated plates. Flow Measurement and Instrumentation 28, 57-66. URL: http://dx.doi.org/10.1016/j.flowmeasinst.2012.07.006, doi:10.1016/j.flowmeasinst.2012.07.006.

Minnick, B.A., Kim, J.W., Ko, D.I., Calabrese, R.V., 2018. Flow and power characteristics of an axial discharge rotor-stator mixer. Chemical Engineering Research and Design 136, 477-490. URL: https://doi.org/10.1016/j.cherd.2018.05.015, doi:10.1016/j.cherd.2018.05.015.

Mortensen, H.H., Arlov, D., Innings, F., Håkansson, A., 2018. A validation of commonly used CFD methods applied to rotor stator mixers using PIV measurements of fluid velocity and turbulence. Chemical Engineering Science 177, 340353. URL: http://linkinghub.elsevier.com/retrieve/pii/S0009250917307169, doi:10.1016/j.ces.2017.11.037.

Mortensen, H.H., Innings, F., Håkansson, A., 2017. The effect of stator design on flowrate and velocity fields in a rotor-stator mixerAn experimental investigation. Chemical Engineering Research and Design 121, 245-254. URL: http://dx.doi.org/10.1016/j.cherd.2017.03.016, doi:10.1016/j.cherd.2017.03.016.

Özcan-Taşkin, G., Kubicki, D., Padron, G., 2011. Power and flow characteristics of three rotor-stator heads. The Canadian Journal of Chemical Engineering 89, 1005-1017. URL: http://doi.wiley.com/10.1002/cjce.20553, doi:10.1002/cjce.20553.

Rielly, C.D., Gimbun, J., 2009. Computational Fluid Mixing. Wiley Blackwell, Chichester. URL: https://dspace.lboro.ac.uk/2134/5446, doi:10.1002/9781444312928.ch8.

Utomo, A., Baker, M., Pacek, A.W., 2009. The effect of stator geometry on the flow pattern and energy dissipation rate in a rotorstator mixer. Chemical Engineering Research and Design 87, 533-542. URL: http://linkinghub.elsevier.com/retrieve/pii/S0263876208003511, doi:10.1016/j.cherd.2008.12.011.

Utomo, A.T., Baker, M., Pacek, A.W., 2008. Flow pattern, periodicity and energy dissipation in a batch rotor-stator mixer. Chemical Engineering Research and Design 86, 1397-1409. URL: http://dx.doi.org/10.1016/j.cherd.2008.07.012, doi:10.1016/j.cherd.2008.07.012. 